\title{
EFFECT OF NEEDLE FREE JET ANESTHESIA COMFORT-IN ON POST EXTRACTION BLEEDING AND INFLAMMATION IN CHILDREN
}

\author{
Mohammed Mohammed Abdelsamad Elabd ${ }^{1 *}$, Alaa aldeen Abdallah Mohamed ${ }^{2}$, Abd-Elhamid Abu-Elyazed ${ }^{3}$
}

\begin{abstract}
Objective: The objective of this study was to assess the needle free jet anesthesia comfort-in on post extraction bleeding and inflammation in children. Subjects \& Methods: The study was performed on 50 Egyptian children patients who needed extraction of teeth, according to the treatment plan, were recruited in the study. The patients were divided into two groups: 25 subjects in the needle free jet anesthesia comfort-in ${ }^{\mathrm{TM}}$ group and 25 subjects in the standard dental aspirating syringe group. Results: It was found that using jet technique resulted in less inflammatory mediators than using syringe technique. Conclusion: Jet technique is a promising technique in anaethesia with a high success rate and showing competitive properties to syringe technique. It has the power to be an alternative for syringe technique
\end{abstract}

KEY WORDS: extraction, anaesthesia, needle free jet, syringe technique.

\section{INTRODUCTION}

After tooth extraction, it is normal for the area to bleed and then clot, generally within a few minutes. It is abnormal if bleeding continues without clot formation, or lasts beyond 8 to 12 hours; this is known as post-extraction bleeding (PEB). Such bleeding incidents can cause distress for patients, who might need emergency dental consultations and interventions. The causes of PEB can be local, a systemic disease, or a medication ${ }^{(1)}$.

Post-extraction bleeding (PEB) is a recognized, frequently encountered complication in dental practice, which is defined as bleeding that continues beyond 8 to 12 hours after dental extraction. The incidence of post-extraction bleeding varies from $0 \%$ to $26 \%{ }^{(2)}$. If this bleeding is not managed, complications can range from soft tissue haematomas to severe blood loss and death. Local causes of bleeding include soft tissue and bone bleeding. Systemic causes include platelet problems, coagulation disorders or excessive fibrinolysis, and inherited or acquired problems (medication induced). There is a wide array of techniques suggested for the treatment of post-extraction bleeding, which include interventions aimed at both local and systemic causes ${ }^{(3)}$. One of this technique use of local anesthetic solution contain vasoconstriction agent ${ }^{(4)}$ or use local anesthetic solution under pressure as Needle Free Jet Anesthesia Comfort-in ${ }^{(5)}$.

1. Masters Candidate, Department of Pedodontics and Oral Health, Faculty of Dental Medicine Boys, Cairo A, Al-Azhar University.

2. Dentist, Ministry of Health

3. Assistant Professor, Department of Pedodontics and Oral Health, Faculty of Dental Medicine, Boys, Cairo, AL-Azhar University

4. Lecturer of Pedodontics and Oral Health, Faculty of Dental Medicine, Boys, Cairo, Al Azhar University.

-Corresponding author: mohamadelabd66@gmail.com

DOI: 10.21608 /ajdsm.2020.40051.1105 
Needle Free Jet Anesthesia Comfort-in delivers liquid medications by creating a very narrow velocity fluid straight line (essentially a "fluid needle") with high pressure spring power through a small orifice in the face of nozzle which penetrates the mucosa and delivers the medicine into the bone with safety from needle injury ${ }^{(5,6)}$.

Inflammation and the innate immune response are involved in the regulatory mechanism responsible for initiating the healing of socket after extraction. Healing takes place in three stages, an inflammatory phase, a proliferative phase and a maturation phase. The inflammatory phase is initiated as soon as blood platelets come into contact with collagen connective tissue, while blood fills in the empty socket. This creates a platelet aggregation that forms a clot (erythrocytes and leukocytes embedded in a fibrin gel). The clot controls the bleeding, but also serves as a support to the successive stages of healing ${ }^{(7)}$.

The platelets produce growth factors and mediators (cytokines) involved in angiogenesis, the Platelet-Derived Growth-Factor (PDGF) and the Transforming-Growth-Factor-beta (TGF-b). The PDGF is linked to the attraction of the neutrophils and the macrophages, and influences the activity of the smooth muscles and the mitogenic properties of the fibroblasts ${ }^{(8)}$. The TGF-b also signals the attraction of the macrophages, that stimulates them to secrete cytokines such as the PDGF, the Tumor Necrosis Factor-alpha $(\mathrm{TNF}-\mathrm{a})^{(9)}$, and interleukin-1 (IL-1) ${ }^{(10)}$.

Although many studies investigated the traditional needles and Needle Free Jet Anesthesia Comfort-in as a pain control tools, however there is no study concern their effect on post-extraction bleeding and inflammation.

\section{SUBJECTS AND METHODS}

This retrospective study was approved by ethical committee of Faculty of Dental Medicine, Boys, Cairo, Al-Azhar University EC Ref No: $157 / 022019 / 143 \mathrm{G}$. All patients were treated at the pediatric dental clinic for Pedodontics and Oral Health Department, Faculty of Dental Medicine, Boys, Cairo, Al-Azhar University. The inclusion criteria for the study were age between 6-14 years, have teeth indicated for extraction and normally health children. Exclusion criteria were patients indicated for general anesthesia, patients have systemic bleeding disorder, patient have allergy to local anesthesia and insecure of local infection at injection site.

A total of 50 patients who needed extraction of teeth, according to the treatment plan, were recruited in the study. The patients were divided into two groups: 25 subjects in the needle free jet anesthesia comfort-in group and 25 subjects in the standard dental aspirating syringe group.

The needle free jet anesthesia comfort-in ${ }^{\mathrm{TM}}$ group received topical anesthesia gel, inject anesthesia solution by needle free jet anesthesia comfort-in, extraction of indicated teeth, collected blood sample from socket and collected blood sample from periphery artery.

The standard dental aspirating syringe group received topical anesthesia gel, inject anesthesia solution by standard dental aspirating syringe and $25 \mathrm{~mm}$ gauge needle, extraction of indicated teeth, collected blood sample from socket and collected blood sample from periphery artery.

The blood sample saved in the refrigerator and was sent to hematologic lab Immunology and Allergy Center, faculty of medicine, Al-Azhar university, for investigation and measurement of 3 cytokines Platelet-Derived Growth-Factor (PDGF), interleukin-1 (IL-1) and Tumor Necrosis Factoralpha (TNF-a) of inflammatory mediators that firstly response to inflammatory phase of healing.

Statistical analysis was performed with IBM $₫ *$ SPSS ${ }^{\Theta}{ }^{\Theta}$ Statistics Version 20 at $95 \%$ confidence interval. One-way ANOVA test, post hoc TUCKEY tests and descriptive statistics were used to compare between techniques and concentrations. The significance level was set to $\mathrm{P} \leq 0,05$. 


\section{RESULTS}

Descriptive statistics and comparison between materials concentration within the same technique:

The study was conducted on two different techniques of injection jet and syringe technique. Each technique was used for 3 different materials IL1, TNF and PDGF. Based on sample size calculation, 50 patients were assessed for the concentration of each material and statistical analysis was done for each technique and material.

For Jet technique, there was a statistically significant difference between IL1, TNF and PDGf as $\mathrm{p}=0.00$. There was a statistically significant difference between IL1 and PDGf, IL1 and TNF and between PDGF and TNF as $\mathrm{p}=0.00,0.00$ and 0.00 respectively. Table (1)

For Syringe technique, there was a statistically significant difference between IL1, TNF and PDGf as $\mathrm{p}=0.00$. there was a statistically significant difference between IL1 and PDGf, IL1 and TNF and between PDGF and TNF as $\mathrm{p}=0.00,0.00$ and 0.00 respectively. Table (1)

\section{Comparison between different materials concen- tration using different techniques:}

The concentration of different materials (IL1, TNF and PDGF) were analyzed based on the measurements conducted from the 50 patients, Table (2).

\section{IL1 concentration}

There was a statistically significant difference between jet and syringe techniques as $\mathrm{p}=0.01$. Concentration of IL1 using syringe is higher than jet technique

\section{TNF concentration}

There was no statistically significant difference between jet and syringe techniques as $p=0.07$ but concentration of TNF using syringe is higher than jet technique figure

\section{PDGF concentration}

There was a statistically significant difference between jet and syringe techniques as $\mathrm{p}=0.005$. Concentration of PDGF using syringe is higher than jet technique.

TABLE (1) Descriptive statistics and comparison between techniques:

\begin{tabular}{|c|c|c|c|c|c|c|c|c|}
\hline & & Mean & $\mathrm{SD}( \pm)$ & Min & Max & CL & $\mathrm{P}$ & Sig \\
\hline \multirow{3}{*}{ Jet } & IL1 & $10.48^{\mathrm{a}}$ & 9.76 & 1.60 & 35.00 & 4.33 & \multirow{3}{*}{0.00} & \multirow{3}{*}{$\mathrm{S}$} \\
\hline & TNF & $34.70^{\mathrm{b}}$ & 17.28 & 6.00 & 64.00 & 7.66 & & \\
\hline & PDGF & $390.23^{c}$ & 114.19 & 200.00 & 610.00 & 50.63 & & \\
\hline \multirow{3}{*}{ Syringe } & IL1 & $16.89^{\mathrm{a}}$ & 6.62 & 6.00 & 35.00 & 3.50 & \multirow{3}{*}{0.00} & \multirow{3}{*}{$\mathrm{S}$} \\
\hline & TNF & $45.45^{\mathrm{b}}$ & 21.17 & 7.00 & 90.00 & 9.79 & & \\
\hline & PDGF & $492.50^{c}$ & 113.73 & 200.00 & 700.00 & 55.05 & & \\
\hline
\end{tabular}

Significance when $p<0.05$. small letters for significance between the row of the same color 
TABLE (2) Comparison between different materials concentration

\begin{tabular}{|c|c|c|c|c|c|}
\hline \multirow{2}{*}{} & \multicolumn{2}{|c|}{ Jet } & \multicolumn{2}{c|}{ Syringe } & \multirow{2}{*}{ P } \\
\cline { 2 - 5 } & Mean & $\mathrm{SD}( \pm)$ & Mean & $\mathrm{SD}( \pm)$ & \\
\hline IL1 & $10.48^{\mathrm{a}}$ & 9.76 & $16.89^{\mathrm{b}}$ & 6.62 & $0.01^{\mathrm{A}}$ \\
\hline TNF & 34.70 & 17.28 & 45.45 & 21.17 & 0.07 \\
\hline PDGF & $390.23^{\mathrm{a}}$ & 114.19 & $492.50^{\mathrm{b}}$ & 113.73 & $0.005^{\mathrm{B}}$ \\
\hline
\end{tabular}

Large letters refer to Significance, $p<0.05$, small letters for significance between the row of the same color

\section{DISCUSSION}

In the management of the child dental patient, efforts are geared toward the preservation of both primary and permanent dentition; this is because the dentition is important for stimulating the development of the dental arches, maintaining normal occlusal relationship, and playing a role in speech development ${ }^{(11)}$.

Loss of natural teeth in the child may be particularly harmful, leading to drifting, tilting, and malposition of the adjacent and succedaneous teeth, when esthetics is impaired as a result of tooth loss, further complications could arise such as psychological stress, disturbances in social interaction by development of negative selfesteem, the cost of correcting and managing these complications may further be a burden to the child and the parents ${ }^{(12)}$.

After tooth extraction, it is normal for the area to bleed and then clot, generally within a few minutes. It is abnormal if bleeding continues without clot formation, or lasts beyond 8 to 12 hours; this is known as post-extraction.

In this study comfort-in free needle anesthetic used to reduce post-extraction bleeding and inflammation. The choice of comfort-in was in accordance with other previous studies that used the comfortinTM in their studies to reduce the pain of needle during anesthesia ${ }^{(13,14)}$. This is because comfort-in is no risks of needle sticks it's fast, safe and easy it's low maintenance, with a long life.

In this study inflammatory mediator Interleukin-1, TNF-alpha, PDGF were used because these mediators the most common mediator appear rapidly during healing of socket ${ }^{(10,15)}$.

In pervious study were done to evaluate the role of PDGF in wood healing in rabbit ${ }^{(16)}$. Some studies impact on the Influence of Interleukin-1on Early Bone Healing ${ }^{(16,17)}$. Other studies were in accordance with this study which considered that TNF-alpha is a major etiologic factor of inflammatory mediator during the bone healing after extraction ${ }^{(9,18)}$.

\section{CONCLUSION}

Under the strict condition of this study it could be concluded that:

Concentration of IL-1 by comfort-in jet free needle is lower than the concentration of IL-1 by dental syringe. Concentration of TNF-alpha by comfortin jet free needle is lower than the concentration of TNF-alpha by dental syringe. Concentration of PDGF by comfort-in jet free needle is lower than the concentration of PDGF by dental syringe. Comfort-in jet free needle can be used to reduce post extraction inflammatory mediator.

\section{REFERENCES}

1. Nagraj S.K, Prashanti E, Aggarwal H, Lingappa A, Muthu MS, Krishanappa SK, Hassan. Interventions for treating post-extraction bleeding. Cochrane Database of Systematic Reviews, 2018.

2. Sumanth K.N, Prashanti E, Aggarwal H, Kumar P, Lingappa A, Muthu MS, Krishanappa SK. Interventions for treating post-extraction bleeding. Cochrane Database of Systematic Reviews, 2016.

3. Farina, R. and L. Trombelli, Wound healing of extraction sockets. Endodontic Topics, 2011. 50: p. 16-43.

4. Malamed, S., Basic injection technique in local anesthesia. Handbook of Local Anesthesia. 5th ed. St. Louis, Mo: Mosby, 2004: p. 159-69. 
5. Stephens, R. and I. Kramer, Intra-oral injections by high pressure jet. Br. Dent. J, 1964. 117: p. 465-476.

6. Margetis, P., E. Quarantillo, and R. Lindberg, Jet injection local anesthesia in dentistry: a report of 66 cases. United States Armed Forces medical journal, 1958. 9: p. 650-634.

7. Abdulkhaleq, L. Assi MA, Abdullah R, Zamri-Saad M, Taufiq-Yap YH, Hezmee MN., The crucial roles of inflammatory mediators in inflammation: A review. Veterinary world, 2018. 11: p. 627.

8. Lin, Z. , Rios HF, Volk SL, Sugai JV, Jin Q, Giannobile WV, Gene expression dynamics during bone healing and osseointegration. Journal of periodontology, 2011. 82: p. 1007-1017.

9. Tomomatsu, N. Aoki K, Alles N, Soysa NS, Hussain A, Nakachi H, Kita S, Shimokawa H, Ohya K, Amagasa T., LPS $\square$ Induced Inhibition of Osteogenesis Is TNF- $\alpha$ Dependent in a Murine Tooth Extraction Model. Journal of Bone and Mineral Research, 2009. 24: p. 1770-1781.

10. Graves, D.T. Nooh N, Gillen T, Davey M, Patel S, Cottrell D, Amar S, IL-1 plays a critical role in oral, but not dermal, wound healing. The Journal of Immunology, 2001. 167: p. 5316-5320.

11. Chen, M.-s., Oral health status and its inequality among education groups: comparing seven international study sites. International journal of health services, 2002. 32: p. 139-161.

12. Adekoya-Sofowora, C., Traumatized anterior teeth in children: a review of the literature. Nigerian journal of medicine: journal of the National Association of Resident Doctors of Nigeria, 2001. 10: p. 151-157.

13. Munshi, A., A. Hegde, and N. Bashir, Clinical evaluation of the efficacy of anesthesia and patient preference using the needle-less jet syringe in pediatric dental practice. Journal of Clinical Pediatric Dentistry, 2002. 50: p. 131-136.

14. Geenen, L., L.A.M. Marks, and L.C. Martens, [Clinical evaluation of the INJEX system, a local anesthesia system without needles: a comfort evaluation study]. Revue belge de medecine dentaire, 2004. 59: p. 149-155.

15. Labow, M. Shuster D, Zetterstrom M, Nunes P, Terry R, Cullinan EB, Absence of IL-1 signaling and reduced inflammatory response in IL-1 type I receptor-deficient mice. The Journal of Immunology, 1997. 159: p. 2452-2461.

16. Lalani, Z. Wong M, Brey EM, Mikos AG, Duke PJ. Spatial and temporal localization of transforming growth factor- $\beta 1$, bone morphogenetic protein- 2 , and platelet-derived growth factor-A in healing tooth extraction sockets in a rabbit model. Journal of Oral and Maxillofacial Surgery, 2003. 61: p. 1061-1072.

17. Wang, X, Luo Y, Masci PP, Crawford R, Xiao Y. Influence of Interleukin-1 Beta on Platelet-Poor Plasma Clot Formation: A Potential Impact on Early Bone Healing. PloS one, 2016. 11: p. e0149775-e0149775.

18. Jung, S., H.-Y. Yang, and T.-H. Lee, Differential expression of immunologic proteins in gingiva after socket preservation in mini pigs. Journal of Applied Oral Science, 2015. 23: p. 187-195. 